\title{
INDICADORES SOCIOAMBIENTAIS DE COMUNIDADES TRADICIONAIS QUE RESIDEM NO ENTORNO DA BAÍA DE TODOS OS SANTOS
}

\author{
Erika Silva Vieira Serbeto ${ }^{1}$ e Fábio Pedro Souza de Ferreira Bandeira ${ }^{2}$ \\ 1. Bolsista PIBIC/FAPESB, Graduando em Bacharelado em Ciências Biológicas, Universid ade Estadual de \\ Feira de Santana, e-mail: erikaserbeto20@ gmail.com \\ 2. Orientador, Departamento de Ciências Biológicas, Universidade Estadual de Feira de Santana, e-mail: \\ fpbandeira@gmail.com
}

PALAVRAS-CHAVE: comunidades tradicionais e locais; Baía de Todos os Santos; categorias de risco.

\section{INTRODUÇÃO}

Do ponto de vista estatal, é atribuído o termo de Povos e Comunidades Tradicionais aos "grupos diferenciados culturalmente e que se auto reconheçam como tais, que tenham próprias maneiras de organização social, utilizam e ocupam territórios e recursos naturais condicionados para a sua reprodução social, cultural, econômica, religiosa e ancestral fazendo o uso de conhecimentos, práticas e inovações gerados e repassados pela tradição. Povos ou Comunidades tradicionais existem em todas as regiões do Brasil, englobando os seringueiros, ribeirinhos, quilombolas, ciganos, castanheiros, povos de terreiro, babaçueiros e outros" (Decreto s/n de 27 de dezembro de 2004). De território de ocupação indígena e forma de paisagem natural, a Baía de Todos os Santos (BTS) se torna o portal principal ao território que mais à frente veio abrigar cidades, municípios, vilas, populações e também patrimônio erigido que conformam a paisagem cultural e humana de toda essa área. No geral, os contornos da BTS abrangem um total de treze municípios, nos quais vivem muitas comunidades ribeirinhas e locais que são impactadas pela forte atividade industrial e petroquímica na região. Baseado nesse contexto, o trabalho em questão teve como objetivo fazer uma análise sistemática da base de dados das comunidades pesqueiras da BTS, do Núcleo de Pesquisa em Ambiente, Sociedade e Sustentabilidade (NUPAS), e na revisão bibliográfica dos indicadores socioambientais de populações tradicionais situadas no entorno dessa Baía.

\section{MATERIAL E MÉTODOS OU METODOLOGIA (ou equivalente)}

Para a realização do trabalho foram escolhidos localidades de três municípios, dentre os treze que contornam a BTS: Ilha de Maré (Salvador), São Francisco do Conde e Itaparica. A Ilha de Maré faz parte da XVI região administrativa da cidade de Salvador. A ilha se encontra na parte nordeste da BTS estando de frente para a Baía de Aratu, na foz do Rio Cotegipe. A ilha conta com onze povoados. São Francisco do Conde, antes pertencente ao Recôncavo Baiano, hoje também faz parte da Região Metropolitana de Salvador. O município se destaca no cenário nacional na lista dos que apresentam maior renda per capta do país, advinda da atividade petroquímica. $\mathrm{O}$ município conta com três grandes distritos, compreendendo diversos povoados. A ilha de Itaparica é a maior das ilhas da BTS. Ela é dividida em dois municípios, Itaparica e Vera Cruz, dispondo de cerca de 24 praias numa extensão de $40 \mathrm{~km}$. A ilha está situada na parte sudoeste da BTS. Para o estudo foram utilizados os dados primários (entrevistas já transcritas) da base de dados do projeto guarda-chuva ("Território redes de cuidado, direitos e vulnerabilidade ambiental entre populações tradicionais da Baía de Todos os Santos (BTS)"). Foram analisadas, categorizadas (Bardin, 2009) e 
sistematizadas 55 entrevistas, de entrevistados nos municípios escolhidos. A análise das respostas e de possíveis padrões, tanto entre entrevistados como entre localidades e gênero, foi realizada por meio de técnicas estatísticas multivariadas (Análise de Cluster) e também graficadas com auxílio do programa Excel.

\section{RESULTADOS E/OU DISCUSSÃO (ou Análise e discussão dos resultados)}

Os riscos mais percebidos pelos entrevistados nos três municípios foram: falta de saneamento básico $(34,5 \%)$, poluição petroquímica da água $(23,6 \%)$, restrições a locais de pesca $(21,8 \%)$, sistema deficitário de saúde $(18,2 \%)$, violência devido ao tráfico de drogas $(14,5 \%)$, poluição petroquímica do ar (10,9\%) (figura 1). Essas categorias de risco foram compartilhadas entre os entrevistados nas localidades dos três municípios, porém cada localidade apresentou categorias de riscos percebidos de maneira particular (figura 2). As duas primeiras categorias mais citadas eram esperadas, pois segundo Hatje e colaboradores (2009), elas são as principais fontes de contaminação da BTS. Muitos municípios não têm estação de tratamento de esgoto e os dejetos são direcionados ao mangue ou ficam a céu aberto, como em Ilha de Maré, ou quando tem ela não está operante, e também pela intensa atividade industrial e petroquímica em toda a região.

$\mathrm{Na}$ análise por gênero se obteve que os riscos mais citados foram citados por ambos homens e mulheres. Isso mostra que as questões de gênero tendem a influenciar pouco na percepção de riscos nessas localidades (figura 3). No entanto, houveram categorias de risco que foram citadas somente por homens e outras apenas pelas mulheres. As categorias citadas por estas últimas estão relacionadas, sobretudo, às questões de saúde, segurança e as que afetam a atividade de mariscagem. Já as categorias citadas pelos homens estão mais relacionadas às questões que afetam a pesca e às questões territoriais. $\mathrm{Na}$ análise multivariada os agrupamentos se deram em detrimento da localidade (figura 4). O resultado corrobora as análises anteriores, porém trás como dado novo o papel da influência da ocupação dos entrevistados na formação dos agrupamentos. O individuo percebe o risco de acordo com a sua realidade, e as atividades que este desempenha para a reprodução sociocultural de seu grupo influenciam sua percepção das ameaças à sobrevivência da família, da comunidade e das tradições culturais. Por último, a análise do discurso dos entrevistados sobre as consequências socioambientais que atribuíam aos riscos percebidos por eles, revelou que a maioria se relacionam com impactos negativos nas atividades de pesca e mariscagem, que são a fonte de renda da maioria dos moradores dessas localidades, principalmente de Ilha de Maré e Ilha de Itaparica.

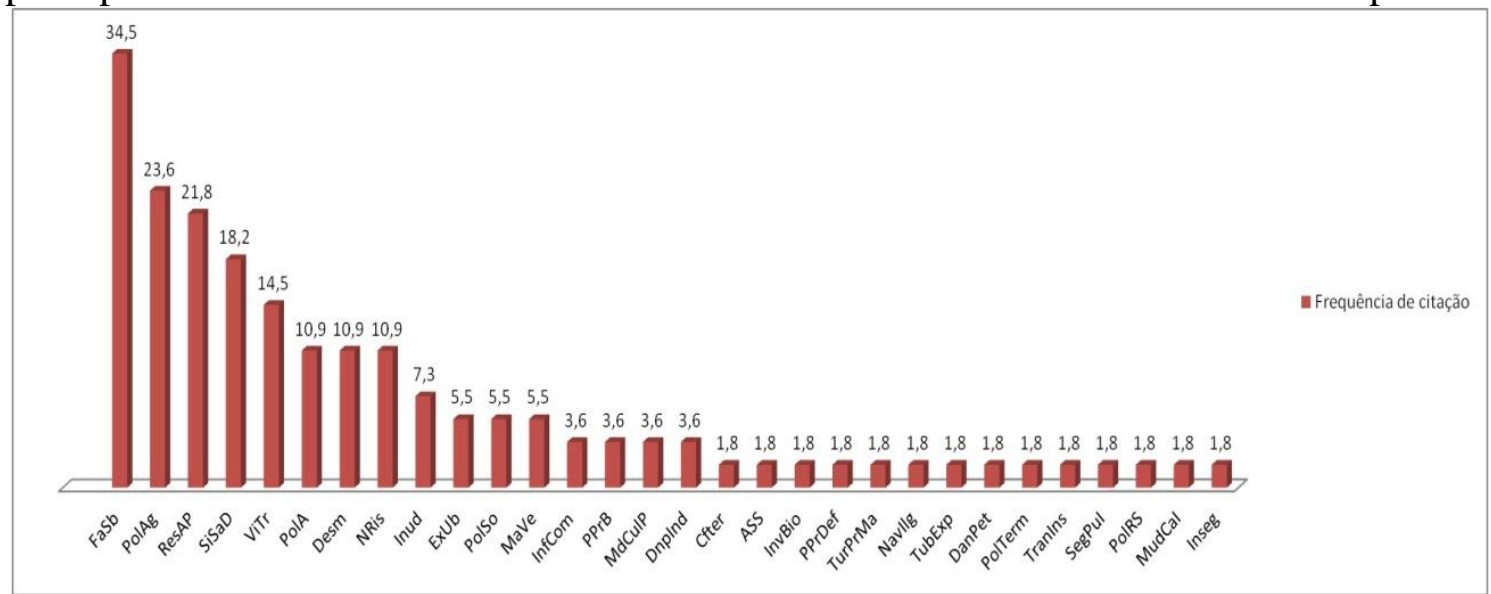

Figura 1. Frequência de citação geral das categorias de risco percebidas por todos os en tre vistados $(n=55)$ das localidades nos muni cípi os de Sal vador (llha de Maré), Ilha de Itaparica e São Francisco do Conde. 


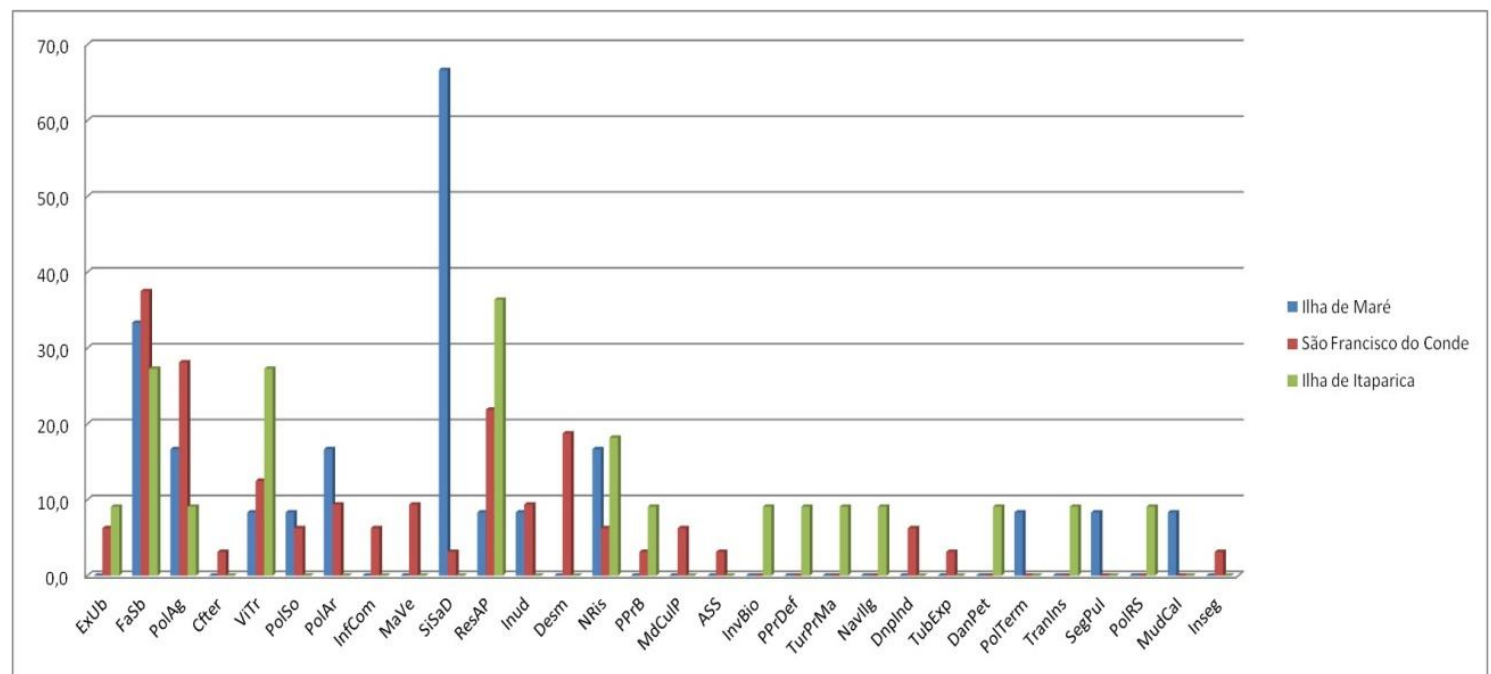

Figura 2. Frequência de citação das categorias de risco pe rce bi das pelos en tre vistados $(n=55)$ por localidades, nos municípi os de Sal vador (llha de Maré), llha de Itaparica e São Francisco do Conde.

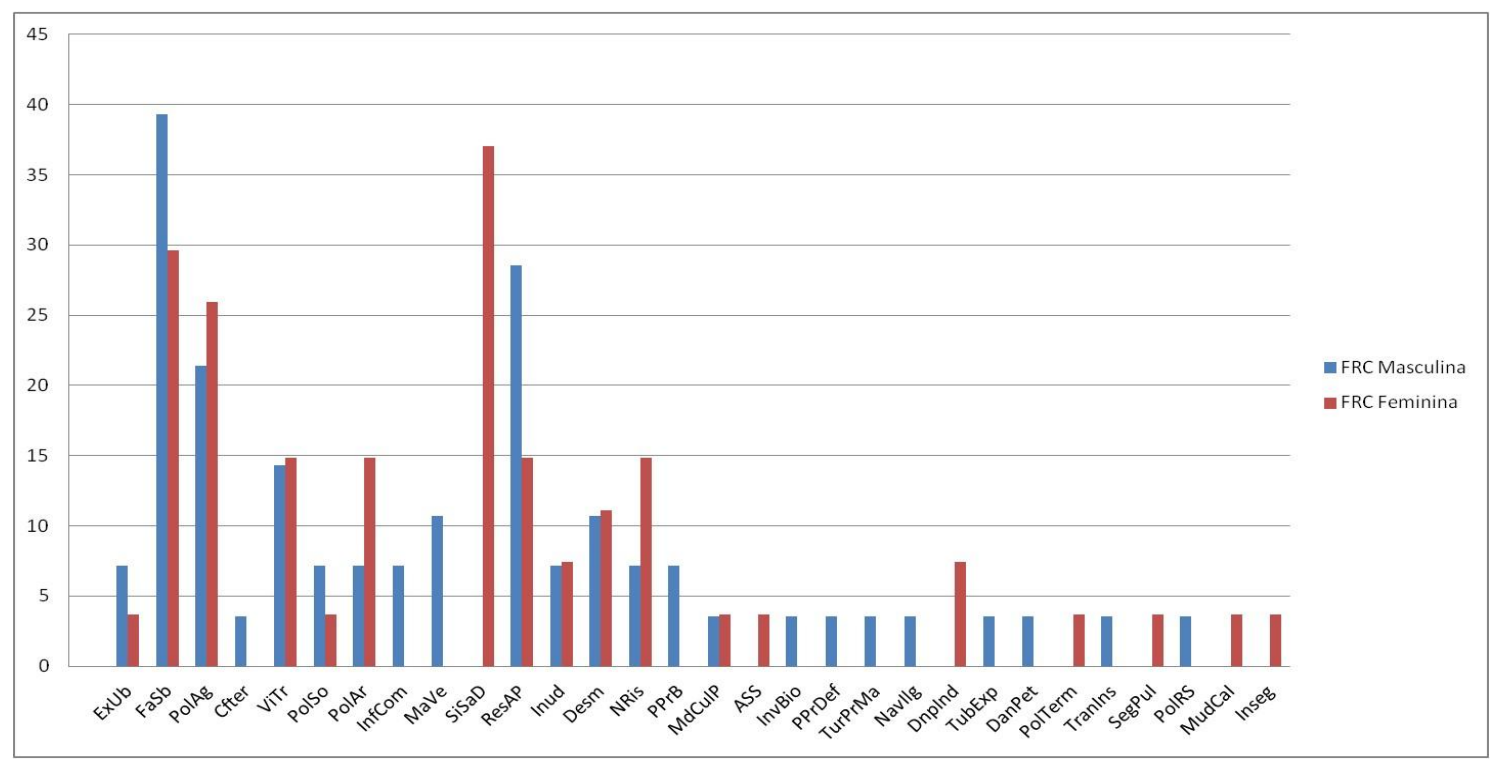

Figura 3. Fre quência de citação geral das categorias de risco pe rcebi das por todos os entre vistados $(n=55)$, por gênero. 


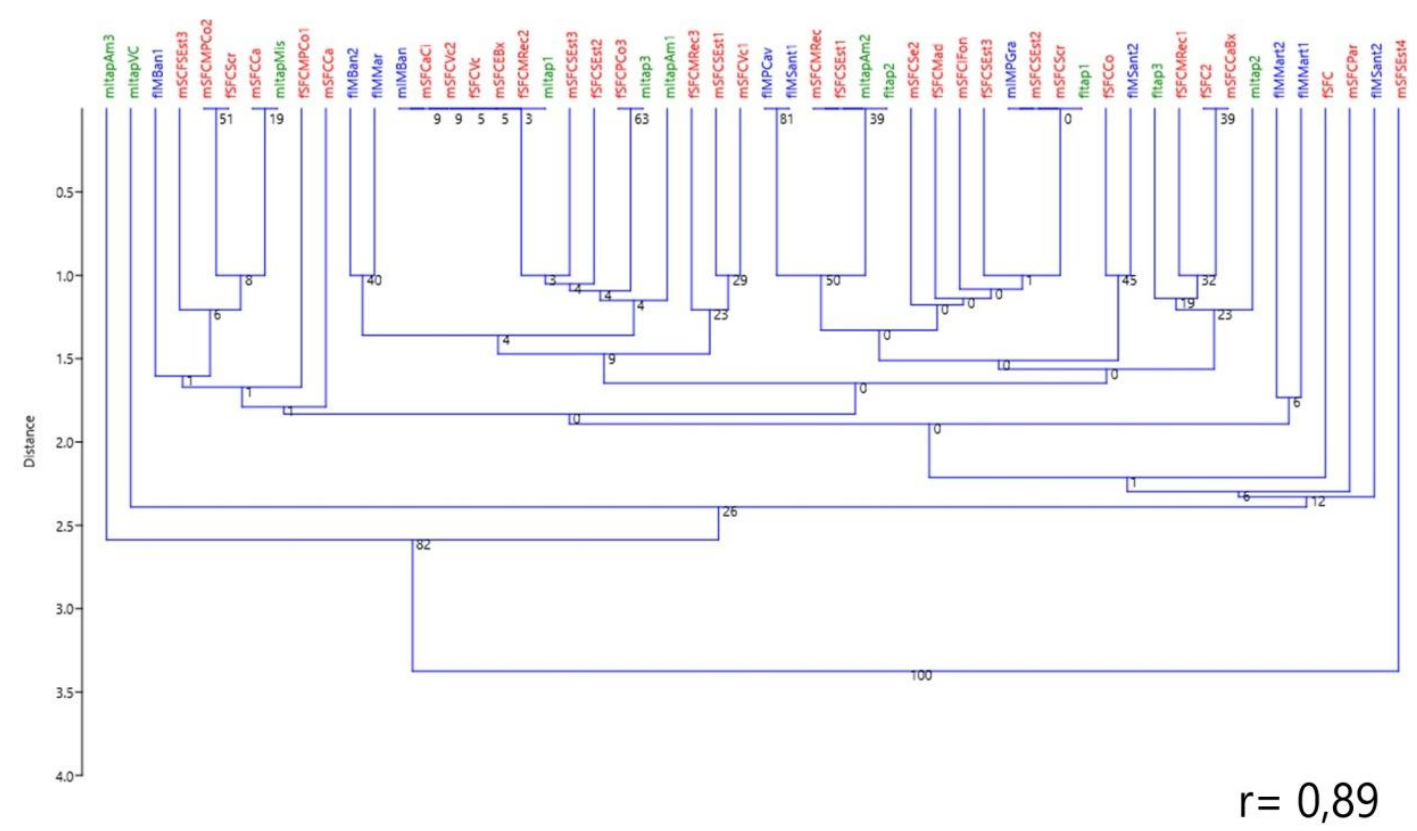

Figura 4. Fenograma dos entre vistados $(n=55)$ obtido com o método de agrupamento UPGMA e o índice de similaridade Distãncia Euclidiana. Legen da: em vermelho são os en tre vistados de São Fran cisco do Conde; em verde são os de Ilha de Itaparica; e em azul são os de llha de Maré. $O$ valor do ín dice de Correlação Cofenética r= $\mathbf{0 , 8 9}$.

\section{CONSIDERAÇÕES FINAIS (ou Conclusão)}

Concluiu-se que os entrevistados das localidades estudadas compartilham uma percepção, em geral, similar de riscos, mas há variações idiossincráticas entre localidades, onde riscos citados em uma localidade não foram citados nas demais. De maneira geral, os riscos mais citados foram percebidos tanto por homens quanto por mulheres, contudo também houveram categorias que foram percebidas apenas por cada gênero. A ocupação é um fator que tende a influenciar na forma de percepção de risco de cada indivíduo. Por fim, as consequências mais apontadas pelos entrevistados nas diferentes localidades são as que afetam as atividades de pesca e mariscagem, das quais a maioria depende economicamente e que fazem parte da construção de sua identidade cultural.

\section{RFERÊNCIAS}

BARDIN, L. Análise de Conteúdo. Lisboa, Portugal; Edições 70, LDA, 2009.

BRASIL(a). Decreto s/n de 27 de dezembro de 2004. Presidência da República. Casa Civil. Subchefia de Assuntos Jurídicos. Acesso: < http://www.planalto.gov.br/ccivil_03/_Ato2004-2006/2004/Dnn/Dnn10408.htm, em 17.mar.2016>.

HATJE et. al. Contaminação química. Baía de Todos os Santos: Aspectos Oceano gráficos. Salvador: EDUFBA, 2009.306p. 